\title{
Assessing the accuracy of microwave radiometers and radio acoustic sounding systems for wind energy applications
}

\author{
Laura Bianco $^{1,2}$, Katja Friedrich ${ }^{3}$, James M. Wilczak ${ }^{2}$, Duane Hazen ${ }^{1,2}$, Daniel Wolfe ${ }^{1,2}$, Ruben Delgado ${ }^{4}$, \\ Steven P. Oncley ${ }^{5}$, and Julie K. Lundquist ${ }^{3,6}$ \\ ${ }^{1}$ Cooperative Institute for Research in Environmental Sciences (CIRES), Boulder, CO, USA \\ ${ }^{2}$ National Oceanic and Atmospheric Administration, Earth Systems Research Laboratory, \\ Physical Science Division, Boulder, CO, USA \\ ${ }^{3}$ Department of Atmospheric and Oceanic Sciences, University of Colorado, Boulder, CO, USA \\ ${ }^{4}$ Atmospheric Physics Department, University of Maryland, Baltimore County, Baltimore, MA, USA \\ ${ }^{5}$ National Center for Atmospheric Research, Boulder, CO, USA \\ ${ }^{6}$ National Renewable Energy Laboratory, Golden, CO, USA \\ Correspondence to: Laura Bianco (laura.bianco@noaa.gov)
}

Received: 28 September 2016 - Discussion started: 12 October 2016

Revised: 6 April 2017 - Accepted: 12 April 2017 - Published: 9 May 2017

\begin{abstract}
To assess current remote-sensing capabilities for wind energy applications, a remote-sensing system evaluation study, called XPIA (eXperimental Planetary boundary layer Instrument Assessment), was held in the spring of 2015 at NOAA's Boulder Atmospheric Observatory (BAO) facility. Several remote-sensing platforms were evaluated to determine their suitability for the verification and validation processes used to test the accuracy of numerical weather prediction models.

The evaluation of these platforms was performed with respect to well-defined reference systems: the BAO's $300 \mathrm{~m}$ tower equipped at six levels $(50,100,150,200,250$, and $300 \mathrm{~m}$ ) with 12 sonic anemometers and six temperature $(T)$ and relative humidity (RH) sensors; and approximately 60 radiosonde launches.

In this study we first employ these reference measurements to validate temperature profiles retrieved by two co-located microwave radiometers (MWRs) as well as virtual temperature $\left(T_{\mathrm{V}}\right)$ measured by co-located wind profiling radars equipped with radio acoustic sounding systems (RASSs). Results indicate a mean absolute error (MAE) in the temperature retrieved by the microwave radiometers below $1.5 \mathrm{~K}$ in the lowest $5 \mathrm{~km}$ of the atmosphere and a mean absolute error in the virtual temperature measured by the radio acoustic sounding systems below $0.8 \mathrm{~K}$ in the layer of the atmosphere covered by these measurements (up to approximately 1.6-
\end{abstract}

$2 \mathrm{~km}$ ). We also investigated the benefit of the vertical velocity correction applied to the speed of sound before computing the virtual temperature by the radio acoustic sounding systems. We find that using this correction frequently increases the RASS error, and that it should not be routinely applied to all data.

Water vapor density (WVD) profiles measured by the MWRs were also compared with similar measurements from the soundings, showing the capability of MWRs to follow the vertical profile measured by the sounding and finding a mean absolute error below $0.5 \mathrm{~g} \mathrm{~m}^{-3}$ in the lowest $5 \mathrm{~km}$ of the atmosphere. However, the relative humidity profiles measured by the microwave radiometer lack the high-resolution details available from radiosonde profiles. An encouraging and significant finding of this study was that the coefficient of determination between the lapse rate measured by the microwave radiometer and the tower measurements over the tower levels between 50 and $300 \mathrm{~m}$ ranged from 0.76 to 0.91 , proving that these remote-sensing instruments can provide accurate information on atmospheric stability conditions in the lower boundary layer. 


\section{Introduction}

While the increasing deployment of wind turbines increases society's reliance on renewably generated electricity, the need for accurate forecasts of that power production is also growing (Marquis et al., 2011). Improving wind forecasts at hub height remains the top priority, but challenges derive from the complexity of physical processes occurring at a wide range of spatial and temporal scales. Fundamental to understanding and accurately forecasting these processes is the accurate measurement of the atmospheric parameters such as wind, temperature, and humidity in four-dimensional space. Assessing the capability and accuracy of remotesensing instruments to capture planetary boundary layer and flow characteristics was one goal of the Department of Energy and NOAA-sponsored eXperimental Planetary boundary layer Instrumentation Assessment (XPIA; Lundquist et al., 2016) campaign conducted in the spring of 2015 at the Boulder Atmospheric Observatory (BAO), located in Erie, Colorado $(\sim 20 \mathrm{~km}$ east of Boulder and $\sim 30 \mathrm{~km}$ north of Denver).

Herein, we address some of the objectives of the XPIA campaign - determining the accuracy of temperature $(T)$, water vapor density (WVD), and relative humidity $(\mathrm{RH})$ profiles from state-of-the-art remote-sensing instruments such as microwave radiometers (MWRs) and Wind Profiling Radars (WPRs) equipped with a Radio Acoustic Sounding System (RASS), and assessing the capability of these active and passive remote-sensing instruments to provide accurate information on atmospheric stability conditions in the lower atmospheric boundary layer. These remote-sensing instruments operated side by side during XPIA and are compared to in situ observations from instruments mounted on a $300 \mathrm{~m}$ meteorological tower and radiosondes.

Several studies have focused on evaluating the accuracy of temperature, water vapor density, and humidity retrieved by MWRs (e.g., Güldner and Spänkuch, 2001; Liljegren et al., 2001; Ware et al., 2003; Crewell and Löhnert, 2007; Cimini et al., 2011; Friedrich et al., 2012; Löhnert and Maier, 2012) and virtual temperature $\left(T_{\mathrm{V}}\right)$ retrieved by WPRs with RASS (May et al., 1989; Moran and Strauch, 1994; Angevine et al., 1998; Görsdorf and Lehmann, 2000). Studies evaluating the accuracy of MWR measurements using radiosonde observations show consistent results with differences of 1$2 \mathrm{~K}$ in temperature, $<0.4 \mathrm{~g} \mathrm{~m}^{-3}$ in water vapor density, and $<20 \%$ in humidity for most weather conditions (Güldner and Spänkuch, 2001; Liljegren et al., 2001; Ware et al., 2003; Crewell and Löhnert, 2007; Cimini et al., 2011; Löhnert and Maier, 2012). Similar results were derived from comparisons between MWR and in situ tower observations with differences in temperature ranging from $0.7-1.7 \mathrm{~K}$ (Crewell and Löhnert, 2007; Friedrich et al., 2012). Studies evaluating the accuracy of RASS measurements using radiosonde and in situ tower observations show root mean square differences of below $1^{\circ} \mathrm{C}$ in virtual temperature (May et al., 1989;
Moran and Strauch, 1994; Angevine et al., 1998). Variations in the results were often a function of various factors such as height above ground, season, topography, abrupt changes in the lapse rate, and regional differences in the surrounding vegetation.

The analysis presented here builds on the results of these previous studies, but also focuses on several unique aspects. First, in our study we provide a comprehensive assessment and comparison of the accuracy of active (two different RASS systems operating side by side in similar modes) and passive (two identical MWRs operating side by side in identical modes) remote-sensing instruments operated over the period of the XPIA campaign under various meteorological conditions, including cold stable air masses, downslope wind conditions, convective conditions, and rain and snow conditions. The accuracies of the retrievals for the two MWR systems were compared to each other as well as to several in situ radiosonde soundings and to the tower observations. Virtual temperatures from a $915 \mathrm{MHz}$ WPR with RASS and a $449 \mathrm{MHz}$ WPR with RASS were also analyzed and compared to in situ radiosonde soundings and tower observations. A second important contribution of this study is to specifically investigate and compare the ability of these active and passive remote-sensing instruments to measure lapse rate to be used, among others, for wind energy applications. Knowing the atmospheric stability is indubitably important for wind energy applications such as wind turbine operations, as atmospheric turbulence and wind shear are affected by changes in atmospheric stability. Furthermore, as found in Warthon and Lunquist (2012), and Vanderwende and Lundquist (2012), atmospheric stability impacts both turbine power production and wake characteristics (Hansen et al., 2012).

This paper is organized as follows: Sect. 2 summarizes the experimental design and instrument characteristics; Sect. 3 and 4 assesses the accuracy of temperature and lapse rates derived from MWRs and RASSs, respectively; and in Sect. 5 water vapor density and humidity from the MWRs are compared to in situ measurements. Finally, conclusions are presented in Sect. 6.

\section{Experimental design, instruments, and methods}

\subsection{Experimental design}

We assess temperature, water vapor density, and relative humidity accuracy from remote-sensing instruments by comparing the observations to in situ observations from radiosondes and instruments mounted on a $300 \mathrm{~m}$ meteorological tower. The remote-sensing instruments include two identical 35-channel (21 in the $22-30 \mathrm{GHz}$ band and 14 in the 51-59 GHz band) Radiometrics MWRs, one $915 \mathrm{MHz}$ WPR equipped with RASS, and one $449 \mathrm{MHz}$ WPR also equipped with RASS. Figure 1 shows the instruments used in this study. A detailed description of the instruments, methods, 

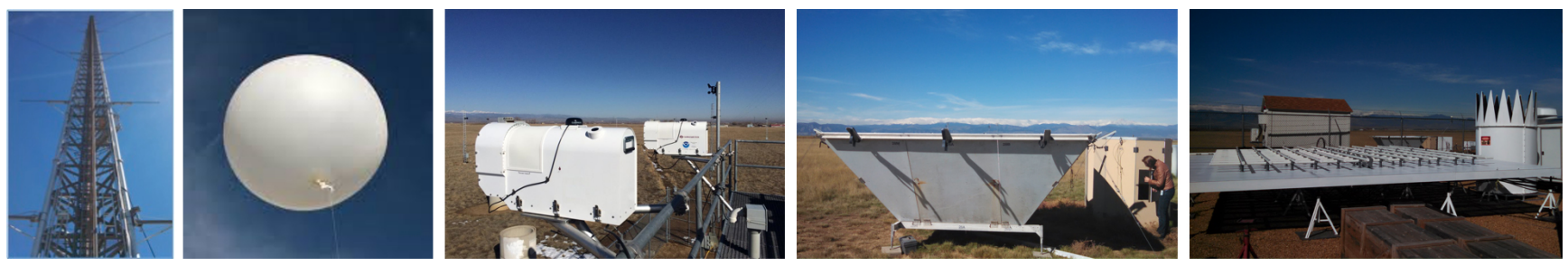

Figure 1. Instruments used in this study. From the left: $300 \mathrm{~m}$ equipped meteorological tower (photo credit: Katie McCaffrey), radiosonde, 2 MWRs, 915 MHz and RASS system (photo credit: Katie McCaffrey), 449 MHz and RASS system (photo credit: Katie McCaffrey).

and their integration into the XPIA campaign can be found in Lundquist et al. (2016). The MWRs and WPR-RASSs operated side by side (few meters apart) at the visitor center, at about $600 \mathrm{~m}$ southwest of the $300 \mathrm{~m}$ meteorological tower. Radiosondes were launched from the visitor center in March (38 soundings), while the remaining 23 soundings were launched in April and May from the water tank site $1000 \mathrm{~m}$ to the southeast of the visitor center (see Fig. 1 in Lundquist et al., 2016 for details).

\subsection{In situ observations: radiosonde and $300 \mathrm{~m}$ meteorological tower}

Radiosondes were launched during fair weather conditions at 08:00 (14:00), 12:00 (18:00), 16:00 (22:00), and 20:00 (02:00) LT (UTC) between 9-19 March (38 soundings), 15 and 20-22 April (10 soundings), and 1-4 May (13 soundings) providing, among others, vertical profiles of temperature, dewpoint temperature, and relative humidity between the surface and $>10 \mathrm{~km}$ above ground level (a.g.l.). Fourteen of these soundings were released during stable atmospheric conditions, while the remaining 47 were launched during unstable conditions.

Two types of sounding systems were used during the campaign: the National Center for Atmospheric Research's Mobile GPS Advanced Upper-Air Sounding System (MGAUS) was used in March (with a $1 \mathrm{~s}$ temporal resolution and an accuracy of $0.25^{\circ} \mathrm{C}$ on temperature and of $1.5 \%$ on relative humidity) for launches from the visitor center, while the Vaisala MW31 DigiCORA sounding system was used in April and May (with a $2 \mathrm{~s}$ temporal resolution and an accuracy of $0.5^{\circ} \mathrm{C}$ on temperature and of $5 \%$ on relative humidity) for launches from the water tank site.

The $300 \mathrm{~m}$ meteorological tower was equipped with temperature and relative humidity sensors at six levels $(50,100$, $150,200,250$, and $300 \mathrm{~m}$ ) operating continuously at a temporal resolution of $1 \mathrm{~s}$. Temperature was measured with an accuracy better than $0.1 \mathrm{~K}$ (Horst et al., 2016).

\subsection{Microwave radiometers}

Two Radiometrics MWRs, one operated by NOAA (referred to as the NOAA MWR hereafter) and one operated by the University of Colorado (CU MWR), ran side by side with identical configurations. Prior to the experiment, both MWRs were calibrated using an external liquid nitrogen target and an internal ambient target (Han and Westwater, 2000) and thoroughly serviced (sensor cleaning, radome replacement, etc.). After calibration, we compared the brightness temperatures of the two MWRs for each retrieved channel for 1 day, finding almost all channels in good agreement (with differences of $\sim 2 \mathrm{~K}$ for channels $51.248,51.760,52.280$, $56.020,57.288,57.964$, and $58.800 \mathrm{GHz}$; differences of $\sim 1 \mathrm{~K}$ for channels $22.500,26.234,30.000,52.804,53.848$, and $56.660 \mathrm{GHz}$; while the remaining channels did not show appreciable differences). However, even a small difference might be enough to skew the retrieval algorithms slightly, contributing to the explanation of some of the differences between the two instruments we will find later in the analysis.

Both MWRs observed at the zenith and at an elevation angle of $15^{\circ}$ above the ground (referred to as $15^{\circ}$ elevation scans hereafter). The instruments were aligned in such a way that the $15^{\circ}$ elevation scans pointed towards the north and south, approximately parallel to the Colorado Front Range. Microwave emissions at the water vapor $(22-30 \mathrm{GHz})$ and oxygen $(51-59 \mathrm{GHz})$ absorption band together with infrared emission at 9.6-11.5 $\mu \mathrm{m}$ were used to retrieve vertical profiles of temperature, water vapor density and relative humidity every $2-3$ min using distinct neural networks that are trained on 5 years of site-specific radiosonde data (Solheim et al., 1998a, b; Ware et al., 2003). The algorithm, based on a radiative transfer model (Rosenkranz, 1998), was trained for both MWRs on a 5-year radiosonde climatology from the Denver, Colorado, National Weather Service sounding archive, based on radiosondes launched at the Denver International Airport, $35 \mathrm{~km}$ to the southeast of the instrument site. Note that the MWR observes within an inverted cone with a $2-3^{\circ}$ beam width at $51-59 \mathrm{GHz}$ and a $5-6^{\circ}$ beam width at $22-30 \mathrm{GHz}$ (Ware et al., 2003). Instruments were placed next to each other on a trailer $\sim 3 \mathrm{~m}$ off the ground and at a distance of $\sim 2 \mathrm{~m}$ to avoid interference. These instruments become less accurate in the presence of rain because of scattering of radiation due to raindrops in the atmosphere; also, although the instruments use a hydrophobic radome and forced airflow over the surface of the radome during rain, some water can still deposit on the radome. It has been observed that retrieved temperature and humidity profiles from 
the $15^{\circ}$ elevation scans provide higher accuracy during precipitation compared to the zenith observations by minimizing the effect of liquid water and ice on the radiometer radome (Xu et al., 2014).

The nominal vertical levels of the retrieved profiles ranged from $50 \mathrm{~m}$ between the surface and $0.5 \mathrm{~km}$ a.g.1., $100 \mathrm{~m}$ between 0.5 and $2 \mathrm{kma}$ a.g.l., and $250 \mathrm{~m}$ between 2 and $10 \mathrm{~km}$ a.g.l. Note that we will refer to these nominal levels as vertical resolution throughout the paper. Both instruments were also equipped with a rain sensor and a surface sensor for observations of temperature, pressure, and relative humidity. These surface observations serve as a boundary condition for the neural network approach. Since the surface sensor from the NOAA MWR was broken between 5 and 27 April, the intercomparison for the NOAA radiometer focuses solely on observations collected between 9 March-4 April and 28 April-7 May 2015, while the intercomparison for the $\mathrm{CU}$ radiometer includes all dates between 9 March and 7 May 2015.

\subsection{WPR-RASS}

Wind profiling radars are primarily used to measure the vertical profile of the horizontal wind vector (Strauch et al., 1984; Ecklund et al., 1988). The remote measurement of virtual temperature in the lower atmosphere is achieved with the associated RASS, co-located with the WPR. Usually a WPRRASS system is set up to operate in wind mode for a large fraction of each hour and in RASS mode for the remaining small fraction. When the system is in RASS mode, the RASS emits a longitudinal acoustic wave upward in the air that generates a local compression and rarefaction of the ambient air. These density variations are tracked by the Doppler radar, and the speed of sound is measured. From the measurement of the speed of sound, the virtual temperature in the boundary layer can be obtained (North et al., 1973).

The $915 \mathrm{MHz}$ WPR RASS settings were selected to sample the boundary layer from 120 to $1618 \mathrm{~m}$ in the vertical with a $62 \mathrm{~m}$ resolution, while the $449 \mathrm{MHz}$ WPR RASS sampled the boundary layer from 217 to $2001 \mathrm{~m}$ with $105 \mathrm{~m}$ resolution.

Several factors can undermine the accuracy in $T_{\mathrm{v}}$ measurements from RASSs. For example, vertical velocity can influence the accuracy of RASS measurements (May et al., 1989; Moran and Strauch, 1994) because the apparent speed of sound measured by the radar is equal to the sum of the true speed of sound and the vertical air velocity. Previous studies (Moran and Strauch, 1994; Angevine and Ecklund, 1994; Görsdorf and Lehmann, 2000) have found conflicting results on the overall accuracy of $T_{\mathrm{v}}$ measurements by RASSs from correcting the speed of sound for the vertical velocity. Görsdorf and Lehmann (2000) found that the vertical velocity correction improves the accuracy of RASS temperature measurements only in situations when the error of the measured vertical velocities is smaller than the magnitude of
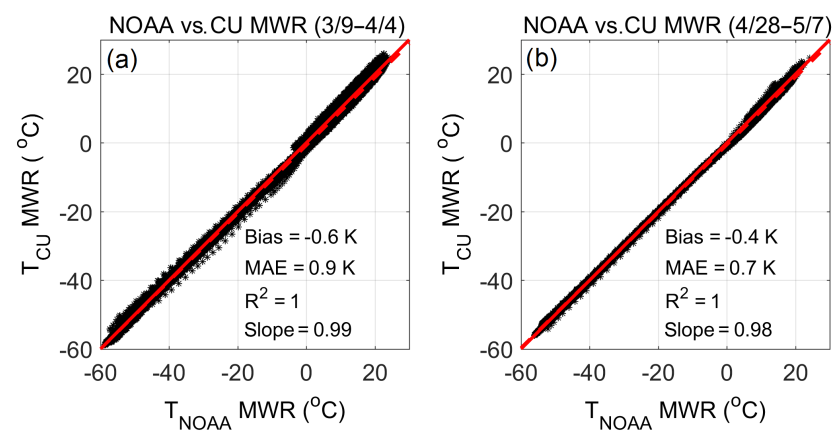

Figure 2. Comparison between temperature observed by CU MWR and NOAA MWR between (a) 9 March-4 April and (b) 28 April-7 May, 2015. The missing days in April coincide with the failure of the NOAA MWR surface sensor. A 1-to-1 line is indicated in solid red, and the regression is shown by the dashed red line.

the vertical velocity itself. This situation is more likely to occur under unstable conditions in the boundary layer. In some cases, they found that this correction can decrease the accuracy of RASS, especially in situations with only light horizontal winds and a lower reliability of vertical wind measurements. Our systems provided both corrected and uncorrected vertical velocity, enabling us to investigate the accuracy of RASS measurements of $T_{\mathrm{v}}$, both corrected and uncorrected for vertical air motion.

Since the volumes sampled by the MWRs and RASSs are substantially larger than those sampled by the soundings or the tower-based measurements, vertical averaging and linear interpolation were used to facilitate comparison. Particularly, when comparing measurements from MWRs and RASSs to sounding observations, we averaged the data of the soundings over the heights of the MWRs and RASSs. When comparing measurements from RASSs to the tower observations we linearly interpolated the data of the tower over the heights of the RASSs, while when comparing measurements from the MWRs to the tower observations no spatial interpolation or averaging was applied since MWR-derived temperature levels $(0,50,100,150,200,250,300 \mathrm{~m})$ were the same height levels as the in situ tower observations.

\section{Accuracy of the temperature profiles}

\subsection{MWRs versus sounding observations}

Differences in temperature between the two MWRs were analyzed before comparing to sounding observations. Profiles derived from the MWR off-zenith scans at $15^{\circ}$ elevation between the surface and $10 \mathrm{~km}$ were compared during the time periods when both instruments were functioning (9 March-4 April 2015 in Fig. 2a; 28 April-7 May 2015 in Fig. 2b). Note that the off-zenith scans towards the north and south were averaged to reduce the impact of any horizontal inhomogeneity of the atmosphere. Although MWRs operated side by side 
Table 1. Statistical values for the NOAA and CU MWRs vs. radiosonde observations of $T$ for the three periods of radiosonde launches and for the zenith and at $15^{\circ}$ off-zenith angles. Bias and MAE are in (K).

\begin{tabular}{|c|c|c|c|c|c|c|c|c|c|c|c|c|}
\hline & \multicolumn{4}{|c|}{ March (38 radiosonde) } & \multicolumn{4}{|c|}{ April (13 radiosonde) } & \multicolumn{4}{|c|}{ May (10 radiosonde) } \\
\hline & Bias & MAE & $R^{2}$ & slope & Bias & MAE & $R^{2}$ & slope & Bias & MAE & $R^{2}$ & slope \\
\hline $\begin{array}{l}\text { CU MWR (zenith) } \\
\text { vs. radiosonde }\end{array}$ & -0.3 & 1.5 & 0.98 & 0.91 & 0.2 & 1.1 & 0.99 & 0.94 & 0.2 & 1.1 & 0.99 & 0.93 \\
\hline $\begin{array}{l}\text { CU MWR ( } 15^{\circ} \text { elevation) } \\
\text { vs. radiosonde }\end{array}$ & -0.8 & 1.5 & 0.98 & 0.93 & -0.2 & 0.9 & 0.99 & 0.97 & -0.3 & 1.1 & 0.98 & 0.97 \\
\hline $\begin{array}{l}\text { NOAA MWR (zenith) } \\
\text { vs. radiosonde }\end{array}$ & -0.5 & 1.4 & 0.98 & 1.03 & \multirow{2}{*}{\multicolumn{4}{|c|}{ Missing data }} & -0.1 & 1 & 0.99 & 1.04 \\
\hline $\begin{array}{l}\text { NOAA MWR }\left(15^{\circ} \text { elevation }\right) \\
\text { vs. radiosonde }\end{array}$ & 0 & 1.3 & 0.98 & 0.94 & & & & & 0.4 & 1 & 0.98 & 0.97 \\
\hline
\end{tabular}
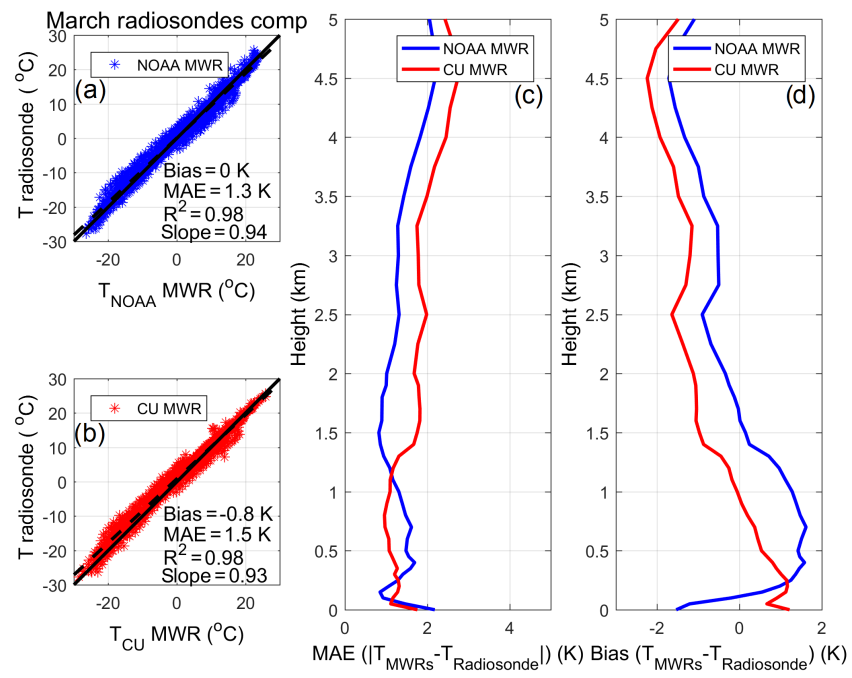

Figure 3. MWRs vs. radiosonde comparison of $T$ for 9-19 March including 38 radiosonde launches: (a-b) one-to-one comparisons between $T$ observed by the radiosondes and the (a) NOAA and (b) CU MWR between the surface and $5 \mathrm{~km}$ a.g.l. One-on-one line is indicated as a solid black line and the regression as a dashed black line. (c-d) Vertical profiles of MAE and bias for the same variable for the NOAA MWR (blue line) and CU MWR (red line).

with exactly the same configurations (Sect. 2.3), mean absolute error between the two systems ranged between 0.7 and $0.9 \mathrm{~K}$ (Fig. 2). Note that the lack of data in April was due to a malfunctioning surface sensor of the NOAA MWR. In general, the CU MWR observed lower temperatures than did the NOAA MWR with the bias between the two instruments, computed as $\left(T_{\mathrm{CU}} \mathrm{MWR}-T_{\mathrm{NOAA}} \mathrm{MWR}\right)$, ranging between -0.4 and $-0.6 \mathrm{~K}$. Since the coefficient of determination, $R^{2}$, value was 1 during the intercomparison period, we consider the two MWRs in good agreement with each other.

For the comparison between MWRs and sounding observations, the data set was divided into three periods in order to account for differences in the sounding systems and their locations as well as differences in the atmospheric con- ditions. The three periods of comparison consist of March, with cooler temperatures and partially snow-covered terrain; May, with mainly warm, convective weather; and a transition period in April with a mixture of cool, rainy and warm, and sunny weather. Differences in temperatures between the MWRs and soundings are shown for March in Fig. 3, April in Fig. 4, and May in Fig. 5 between the surface and $5 \mathrm{~km}$ a.g.l. Scatter plot comparisons between soundings and the radiometer observations show that MAEs in temperature were slightly larger in March, ranging between 1.3 and $1.5 \mathrm{~K}$ (Fig. 3a-b) compared to April and May, where values ranged between 0.9 and $1.1 \mathrm{~K}$ (Figs. 4a, 5a-b). As previously indicated in Fig. 2, the CU MWR underestimated the temperatures compared to the sounding observations with a bias of -0.2 to $-0.8 \mathrm{~K}$ in March, April, and May. The NOAA MWR showed no bias (defined as $T_{\mathrm{MWR}}-T_{\text {Radiosonde) }}$ in March but overestimated temperatures in May with a bias of $0.4 \mathrm{~K}$.

Temperatures derived from the MWR zenith scans were also compared to the sounding observations as presented in Table 1. In the present data set the zenith measurements performed better than the averaged $15^{\circ}$ elevation scans in terms of bias for the CU MWR in March, but not for the NOAA MWR. Despite the better coverage through the boundary layer from the $15^{\circ}$ elevation scans, values of MAE and $R^{2}$ are surprisingly almost identical for the off-zenith and zenith MWR measurements for all three periods. Slopes are closer to 1 for the $15^{\circ}$ elevation scans. We decided to base the rest of the study on off-zenith-averaged observations at a $15^{\circ}$ elevation angle because $15^{\circ}$ elevation scans provide higher accuracy compared to the zenith observations during precipitation (Xu et al., 2014).

MAE in temperature between the MWRs and radiosondes as a function of height, shown in Figs. 3c, $4 b$, and 5c, indicates two different patterns in the cooler March conditions compared to a warmer April and May. In March, MAEs were below $2 \mathrm{~K}$ at altitudes below $3.5 \mathrm{~km}$ for the CU MWR, with a continuous increase up to $2.7 \mathrm{~K}$ at $4.5 \mathrm{~km}$ a.g.l. (Fig. 3c). The NOAA MWR showed a similar behavior with a slightly lower MAE than the CU MWR. In April and May, however, 

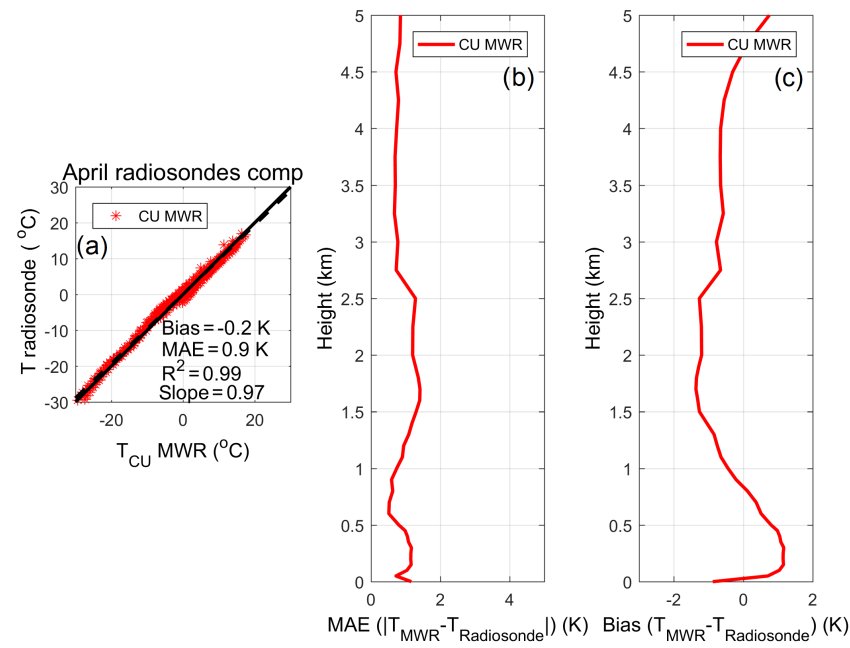

Figure 4. Same as in Fig. 3, but for 15 and 20-22 April including 10 radiosonde launches. Note that the surface sensor of the NOAA MWR was broken between 5 and 27 April; therefore, the NOAA MWR vs. radiosonde comparison $(T)$ over this period is not presented.

MAEs were below $\sim 2 \mathrm{~K}$ at all levels not showing the increase in MAE that was seen in March above $3.5 \mathrm{~km}$.

Bias in temperature between the MWRs and radiosondes as a function of height (Figs. 3d, 4c, 5d) showed mostly negative bias in a shallow layer near the surface, positive values below $\sim 1 \mathrm{~km}(\sim 1.5 \mathrm{~km})$ for the CU (NOAA) MWR, and mostly negative values above. For the March comparison, we notice that biases near the surface are opposite for the NOAA MWR and CU MWR (Fig. 3d). Since surface observations of temperature and pressure are important for the retrieval algorithm, we analyzed surface observations of the two MWRs. Differences in surface pressures between the two MWRs of the order of $\sim 6$ mbar were observed for the March period and only $\sim 1$ mbar for the May period, while differences in surface temperature between the two MWRs of the order of $1.7 \mathrm{~K}$ were observed for the March period and only $0.8 \mathrm{~K}$ for the May period. We can expect that the differences of $\sim 6$ mbar and $1.7 \mathrm{~K}$ between the NOAA and CU MWRs surface sensors might be the cause of the opposite biases found at the lowest levels of Fig. 3d, while those of Fig. 5d, after the surface sensor was replaced and the differences were smaller, are of the same sign. The negative bias below $250 \mathrm{~m}$ is related to the surface inversions often observed at night or early morning (an example of which is shown in Fig. 6a). The details of the inversion were often in error, with the MWRs too cold at the surface and too warm above a few hundred meters due to the inversion height being displaced too high. Above $1.5 \mathrm{~km}$, for some of the profiles, radiosonde temperatures strongly differed from the MWR observations (an example of which is shown in Fig. 6b), which might be related to the presence of elevated temperature inversions that cannot be detected by the MWR or to strong observed winds
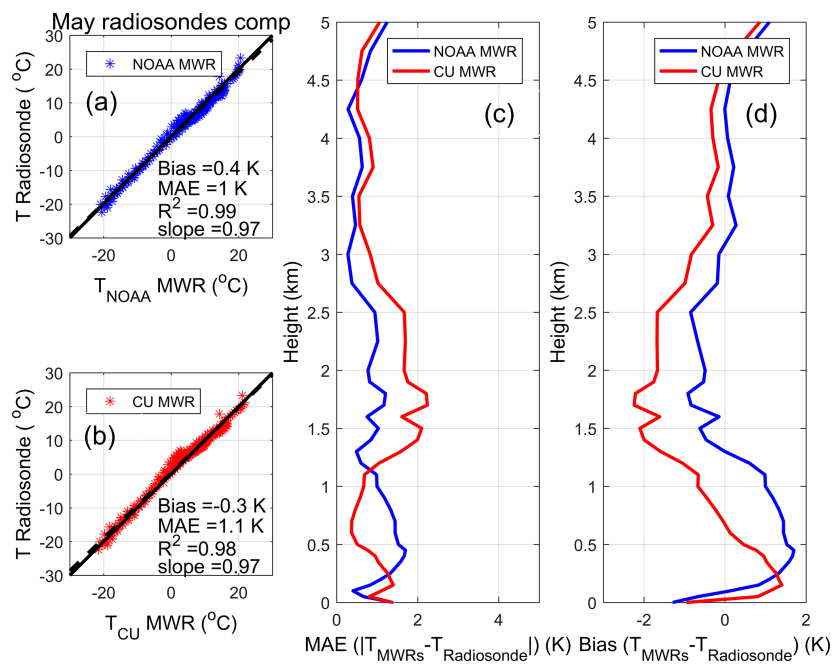

Figure 5. Same as in Fig. 3, but for the May period of 13 radiosonde launches.

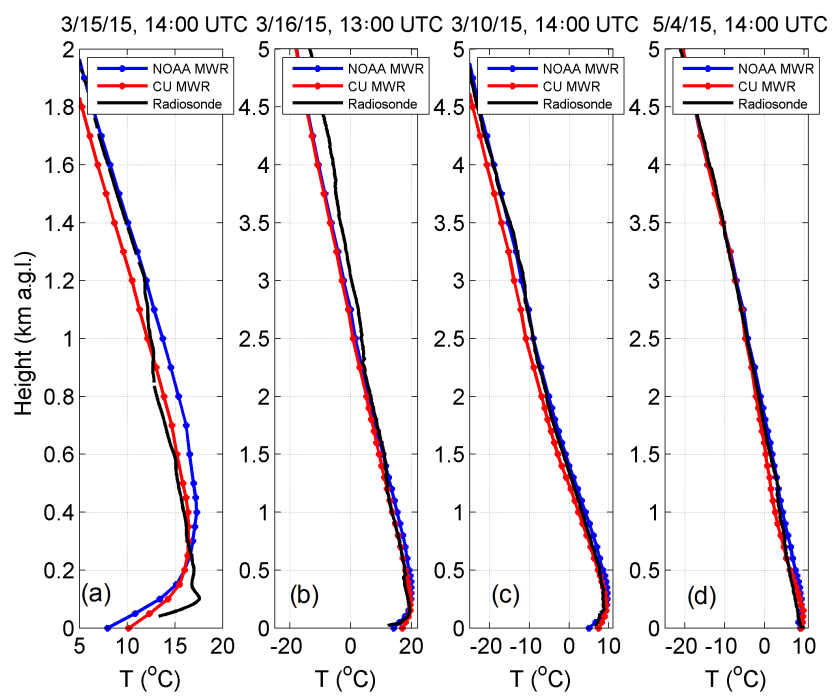

Figure 6. Vertical profiles of temperature as observed by MWRs (blue line: NOAA MWR; red line: CU MWR) and radiosonde (black line) at (a) 08:00 LT (14:00 UTC) on 15 March, (b) 07:00 LT (13:00 UTC) on 16 March, (c) 08:00 LT (14:00 UTC) on 10 March 2015, and (d) 08:00 LT (14:00 UTC) on 4 May 2015.

aloft (winds larger than $10 \mathrm{~m} \mathrm{~s}^{-1}$ were observed for these circumstances, not shown) that transported the sounding farther away from the MWR encountering different air masses. Despite their coarser resolution, the MWRs were capable of capturing important gradients in the temperature profile - the existence or lack of surface temperature inversions at around a few hundred meters a.g.l. and the overall decrease in temperature with height (examples of which are shown in Fig. 6c-d).

To further evaluate how the transition from a stable nighttime to a more convective boundary layer during the day 

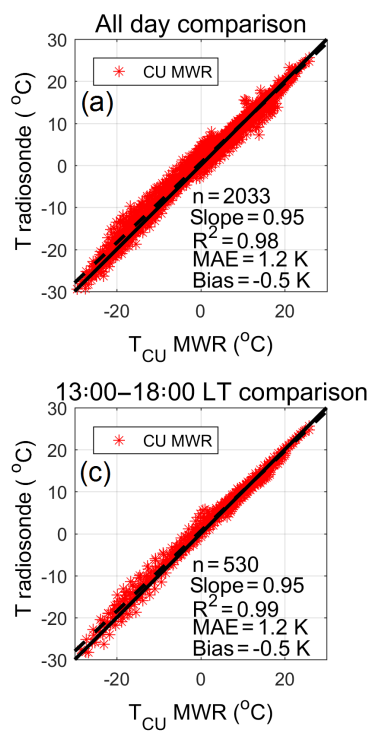
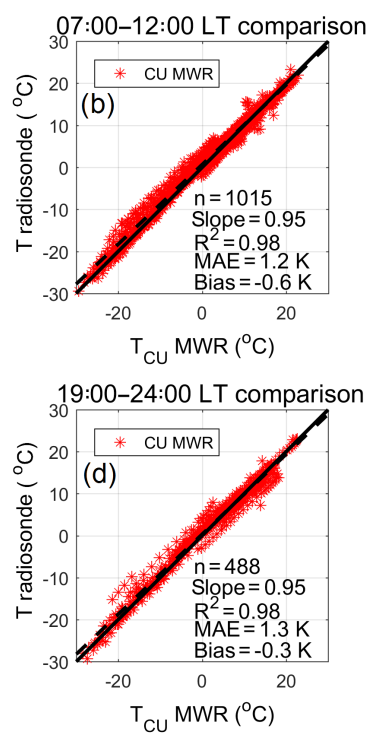

Figure 7. CU MWR vs. radiosonde comparison of temperature over (a) 07:00-24:00 LT, (b) 07:00-12:00 LT, (c) 13:00-18:00 LT, and (d) 19:00-24:00 LT between the surface and $5 \mathrm{~km}$ a.g.l. Data were collected on 9-19 March (38 soundings), 15 April and 20-22 April (10 soundings), and 1-4 May (13 soundings). Note that no radiosondes were launched between 01:00 and 06:00 LT. One-on-one line is indicated as a solid black line and the regression as a dashed black line.

might affect the accuracy of the temperature observation, the CU MWR retrieved temperatures were compared to the radiosonde temperatures at different times of the day (07:0012:00; 13:00-18:00; 19:00-24:00 LT), as presented in Fig. 7. This figure contains only the CU MWR because the CU and NOAA MWR were in good agreement over the two periods presented in Fig. 2 and the CU MWR has a larger data due to continuous operations. No significant differences between these different times of the day were noticed. For this reason, it can be concluded that the MWR was capable of retrieving temperatures with a MAE of around 1.2-1.3 K during different atmospheric stability conditions. In summary below $3.5 \mathrm{~km}$ we find consistent behavior of the MWRs among the different months and similar error statistics for different times of the day using MWR data up to $5 \mathrm{~km}$.

\subsection{RASS versus sounding observations}

Temperature observations from the RASSs were compared to radiosonde observations in the same manner as for the MWRs. As mentioned in Sect. 2.4, we investigate the accuracy of $T_{\mathrm{v}}$ RASS measurements corrected and uncorrected for vertical air motion. Without the vertical velocity correction (uncorrected $T_{\mathrm{V}}$ ), no important differences between the three periods of radiosonde launches emerged (figure not shown). Results of the comparison between uncorrected $T_{\mathrm{v}}$ measurements from the $915 \mathrm{MHz}$ and the $449 \mathrm{MHz}$ RASS and all the radiosondes launched in March, April, and May

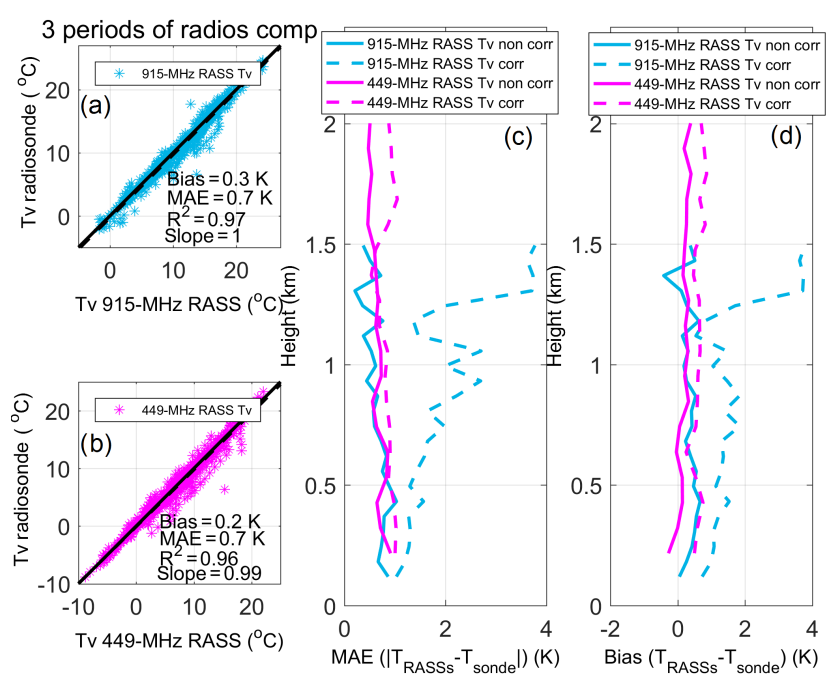

Figure 8. A $915 \mathrm{MHz}$ RASS (light blue) and $449 \mathrm{MHz}$ RASS (magenta) vs. radiosonde comparison of $T_{\mathrm{V}}$ over the three periods (March, April, and May) of radiosonde launches combined together. (a-b) One-to-one comparison between radiosonde and (a) $915 \mathrm{MHz}$ between $120 \mathrm{~m}$ and $\sim 1.6 \mathrm{~km}$ a.g.l. and (b) $449 \mathrm{MHz}$ RASS between $217 \mathrm{~m}$ and $\sim 2 \mathrm{~km}$ a.g.l. The correction for the vertical velocity was not applied. One-on-one line is indicated as a solid black line and the regression as a dashed black line. (c-d) Vertical profiles of MAE and bias for $T_{\mathrm{V}}$ with (dashed lines) and without (solid lines) vertical velocity correction.

are presented in Fig. 8a, b. The MAE for uncorrected $T_{\mathrm{v}}$ observations was $0.7 \mathrm{~K}$, with a bias of $0.2-0.3 \mathrm{~K}$ (defined as $\left.T_{\text {RASS }}-T_{\text {Radiosonde }}\right)$.

The impact of the vertical velocity correction is shown in the profile of MAE (Fig. 8c). For uncorrected $T_{\mathrm{V}}$ (solid lines), MAEs are below $1 \mathrm{~K}$ throughout the entire RASS sampling height. However, for corrected $T_{\mathrm{v}}$ (dashed lines), MAEs are larger than those for the uncorrected $T_{\mathrm{V}}$ for both the 915 and $449 \mathrm{MHz}$ RASS, with larger values for the $915 \mathrm{MHz}$ RASS Similar results were also found for vertical profiles of the bias (Fig. 8d) for both RASSs. The bias is around $0.3 \mathrm{~K}$ for the $915 \mathrm{MHz}$ RASS and remains nearly constant with height (solid blue line); the $449 \mathrm{MHz}$ RASS indicates slightly negative biases below $400 \mathrm{~m}$ (solid magenta line), increasing to around $0.2 \mathrm{~K}$ above. For both RASSs, the use of the vertical velocity correction in the computation of $T_{\mathrm{v}}$ increases the bias substantially (dashed lines), similarly to the impact on the MAE generated by this correction. This data set included little convective activity, and so using the values of $T_{\mathrm{v}}$ corrected for the vertical velocity from RASS measurements is not beneficial in this study, consistent with the results of Görsdorf and Lehmann (2000). Moreover, the correction is more negative on the $915 \mathrm{MHz}$ RASS $T_{\mathrm{v}}$, which is in agreement with the fact that the vertical velocity measurements are less accurate for this system compared to the $449 \mathrm{MHz}$ RASS (Ecklund et al., 1990). 


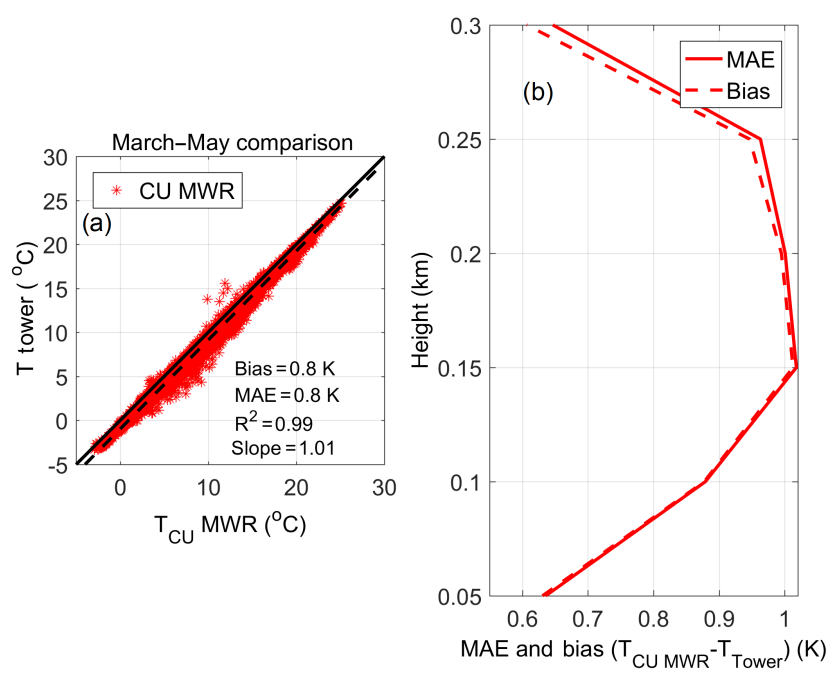

Figure 9. CU MWR vs. tower comparison of temperature for all dates between 9 March and 7 May. (a) One-to-one comparison. One-on-one line is indicated as a solid black solid line and the regression as a dashed black line. (b) Vertical profiles of MAE and bias for the same variable. Temperatures were observed at the tower at 50,100,150, 200, 250, and $300 \mathrm{~m}$ a.g.l., co-located with MWR levels.
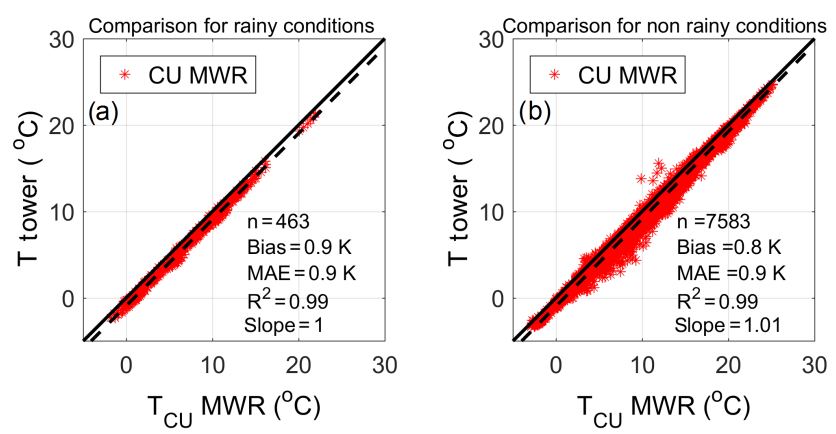

Figure 10. CU MWR vs. tower temperature measurements during (a) rainy conditions and (b) no-rain conditions as measured by the CU MWR. One-on-one line is indicated as black solid line and the regression as a dashed black line.

\subsection{MWRs versus in situ tower observations}

In the next step of our assessment, hourly averaged temperatures from the in situ tower observations were compared to temperatures derived by the CU MWR for all dates between 9 March and 7 May (Fig. 9). The data set was not divided in different months since the overall statistics in Sect. 3.1 indicated little variation between the months. The CU MWR is in better agreement with the tower observations, with a MAE of $0.8 \mathrm{~K}$ (Fig. 9a), than it was with the sounding observations $(\mathrm{MAE}=1.2 \mathrm{~K}$; Fig. 7a). The MWR temperatures show a positive bias of $0.8 \mathrm{~K}$ compared to the in situ temperature observations. The vertical profile of MAE calculated between the MWR and in situ temperature observa-

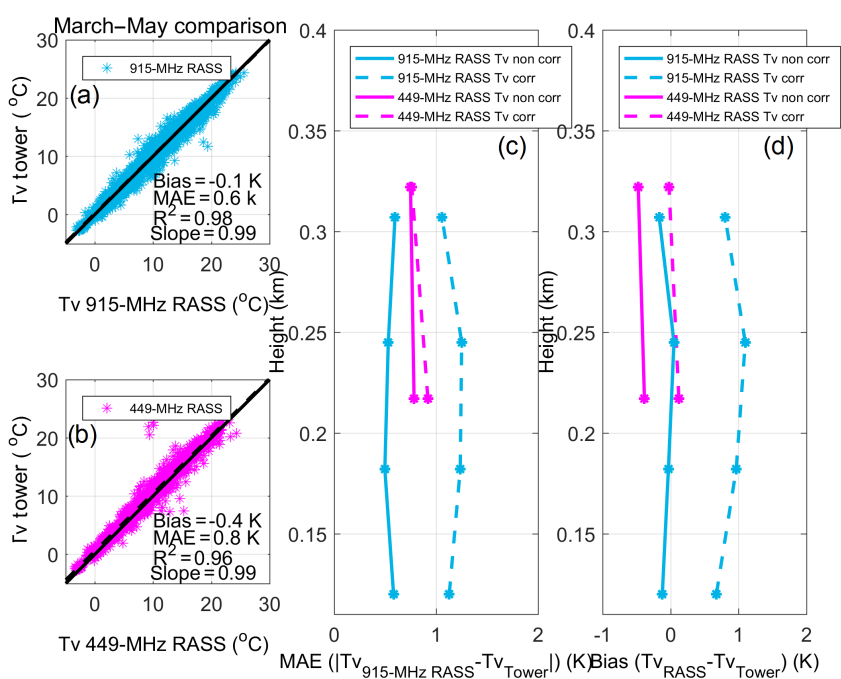

Figure 11. A $915 \mathrm{MHz}$ (light blue) and $449 \mathrm{MHz}$ (magenta) RASS vs. tower comparison of $T_{\mathrm{V}}$ for all dates between 9 March and 7 May. (a-b) One-to-one comparisons between in situ tower observations and uncorrected $T_{\mathrm{V}}$ observations. One-on-one line is indicated as a solid black line and the regression as a dashed black line. (cd) Vertical profiles of MAE and bias for $T_{\mathrm{V}}$ with (dashed lines) and without (solid lines) the vertical velocity correction. Height is a.g.l.

tions (Fig. 9b, solid line) indicates higher values of $\sim 1 \mathrm{~K}$ at $150-250 \mathrm{~m}$, which are exactly the heights where the MAE between the MWR and the radiosondes showed a local maximum in MAE (Figs. 3c, 4b, 5c). The vertical profile of bias in temperature between MWR and in situ observations (Fig. 9b, dashed line) shows that the bias is the main contribution to the error, as the value of the bias and of the MAE are very similar to each other.

While radiosondes were only launched during rain- and snow-free conditions, the comparison with tower observations (Fig. 9) contains measurements during both times with precipitation and without precipitation. A comparison between MWR and in situ temperatures observations from the tower (Fig. 10) shows that the MAE was slightly lower during rainy conditions $(0.8 \mathrm{~K})$ than during rain-free conditions $(0.9 \mathrm{~K})$, but the overall statistics are not particularly compromised. Note that we used the rainfall sensor that MWRs are equipped with to divide the data set between times with and without precipitation.

\subsection{RASS versus in situ tower observations}

Hourly averaged temperatures from the in situ tower observations were compared to temperatures derived by the RASSs for all dates between 9 March and 7 May (Fig. 11). Again, the data set was not divided in different months since the overall statistics in Sect. 3.2 indicated little variation between the months. Since RASS $T_{\mathrm{v}}$ profiles provided data at different heights than the tower observations, hourly averaged tower measurements were linearly interpolated/extrapolated to the 

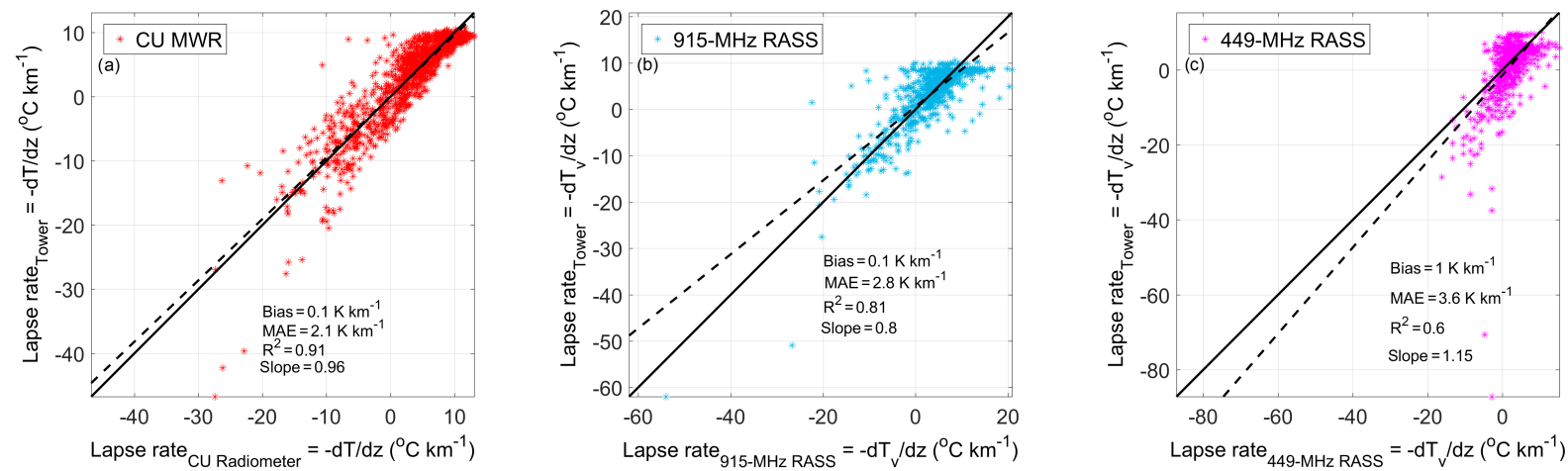

Figure 12. Comparison of atmospheric lapse rate for all dates between 9 March and 7 May, 2015 for (a) CU MWR vs. tower (between first and last level of the tower measurements, 50-300 m), (b) $915 \mathrm{MHz}$ RASS vs. tower (between first and fourth level of the $915 \mathrm{MHz}$ RASS measurements, 120-307 m), and (c) 449 MHz RASS vs. tower (between first and second level of the 915 MHz RASS measurements, $217-$ $322 \mathrm{~m}$ ). Negative lapse rate represents stable atmospheric conditions. One-on-one line is indicated as a solid black line and the regression as a dashed black line.

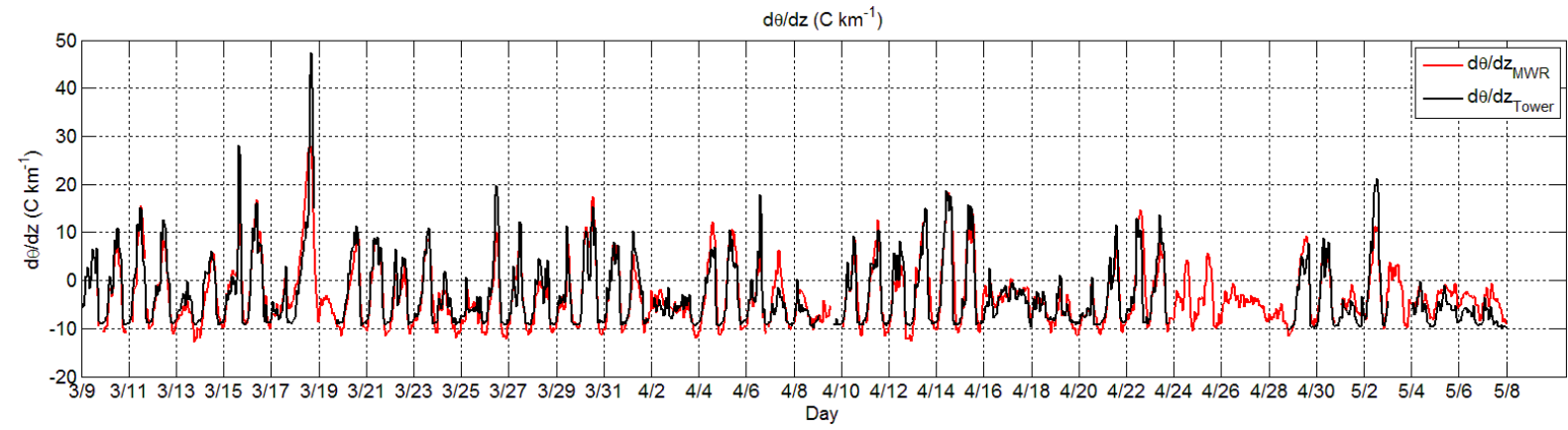

Figure 13. Lapse rate of potential temperature between 50 and $300 \mathrm{~m}$ a.g.l. derived from observations conducted by the CU MWR (red line) and from tower observations (black line) for all dates between 9 March and 7 May.

$915 \mathrm{MHz}$ RASS's lowest four altitudes (120, 182, 245, and $307 \mathrm{~m}$ ) and over the $449 \mathrm{MHz}$ RASS's lowest two altitudes (217 and $322 \mathrm{~m}$ ). As for the comparison with the radiosondes presented in Sect. 3.2, the effect of applying the correction for the vertical velocity to the $T_{\mathrm{V}}$ computation by the RASS systems was again investigated.

For the uncorrected $T_{\mathrm{v}}$, the MAE for the RASSs were similar when using the in situ tower observations (Fig. 11ab) as when using the radiosonde observations (Fig. 8a-b). For bias, both RASSs slightly underestimated virtual temperatures compared to the tower observations, with a bias of $-0.1 \mathrm{~K}$ for the $915 \mathrm{MHz}$ RASS and $-0.4 \mathrm{~K}$ for the $449 \mathrm{MHz}$ RASS. These numbers are within the expected accuracy of RASS measurements (May et al., 1989).

Vertical profiles of uncorrected $T_{\mathrm{v}}$ MAEs and biases calculated between the tower and both the 915 and $449 \mathrm{MHz}$ RASSs (solid blue and magenta lines in Fig. 11c-d) show more accurate results than when using the RASS vertical velocity correction (dashed blue and magenta lines). As previously found in Sect. 3.2, the vertical velocity correction (dashed lines) was not beneficial to either the $915 \mathrm{MHz}$ or the $449 \mathrm{MHz}$ RASS for this data set.

We note that, comparing Figs. 3-5 to 8, and Figs. 9 to 11, the RASS has a lower error statistics than the MWRs, which was also shown in Fig. 15 of Lundquist et al. (2016).

\section{Accuracy of the lapse rate}

Several studies have suggested that surface temperature inversions might be smoothed by remote-sensing instruments with coarse spatial resolutions (Solheim et al., 1998b; Reehorst, 2001). Nevertheless, accurate representation of the lapse rate and consequently of atmospheric stability is essential in many applications and also for wind energy operators to better predict the presence of vertical wind shear (more likely to happen during stable conditions) and turbulence affecting the load on rotors (more likely to happen during unstable conditions). Although it is more appropriate to use the lapse rate of potential temperature or virtual potential temperature to provide information on stability conditions (Friedrich et al., 2012), as a first step we want to evaluate 
Table 2. Statistical values for the CU MWRs vs. tower observations of lapse rate $\left(\gamma_{\theta}=-\mathrm{d} \theta / \mathrm{d} z\right)$ for different tower levels. Bias and MAE are in $\left(\mathrm{K} \mathrm{km}^{-1}\right)$.

\begin{tabular}{rrrr|rrrr|rrr|rrrrr}
\hline $\begin{array}{c}\text { Lapse rate }\left(\gamma_{\theta}=-\mathrm{d} \theta / \mathrm{d} z\right) \\
\text { between } 50 \text { and } 150 \mathrm{~m}\end{array}$ & \multicolumn{2}{|c|}{$\begin{array}{c}\text { Lapse rate }\left(\gamma_{\theta}=-\mathrm{d} \theta / \mathrm{d} z\right) \\
\text { between } 50 \text { and } 200 \mathrm{~m}\end{array}$} & \multicolumn{2}{|c|}{$\begin{array}{c}\text { Lapse rate }\left(\gamma_{\theta}=-\mathrm{d} \theta / \mathrm{d} z\right) \\
\text { between } 50 \text { and } 250 \mathrm{~m}\end{array}$} & \multicolumn{2}{c}{$\begin{array}{c}\text { Lapse rate }\left(\gamma_{\theta}=-\mathrm{d} \theta / \mathrm{d} z\right) \\
\text { between } 50 \text { and } 300 \mathrm{~m}\end{array}$} \\
\hline Bias & MAE & $R^{2}$ & slope & Bias & MAE & $R^{2}$ & slope & Bias & MAE & $R^{2}$ & slope & Bias & MAE & $R^{2}$ & slope \\
\hline 0.76 & 5.7 & 0.76 & 0.59 & 0.52 & 4.0 & 0.82 & 0.70 & -0.19 & 3.0 & 0.88 & 0.81 & -0.1 & 2.2 & 0.91 & 0.96 \\
\hline
\end{tabular}
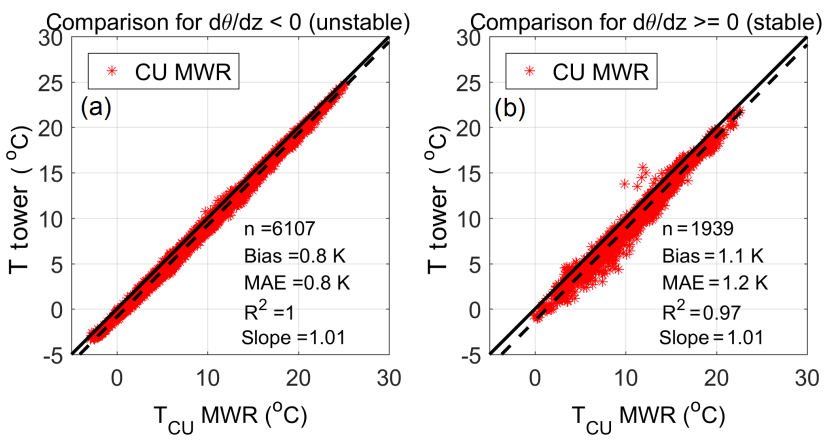

Figure 14. CU MWR vs. tower comparison of $T$ for all dates between 9 March and 7 May, for (a) $\mathrm{d} \vartheta / \mathrm{d} z \geq 0$ between 50 and $300 \mathrm{~m}$. Stability was determined by temperature differences measured by the CU MWR. One-on-one line is indicated as a solid black line and the regression as a dashed black line.

the ability of the MWR and the RASS to accurately capture atmospheric stability conditions in the lower boundary layer. To allow this comparison, we first computed the lapse rate of temperature $\left(\gamma_{T}=-\mathrm{d} T / \mathrm{d} z\right)$ between $50 \mathrm{~m}$ and $300 \mathrm{~m}$ observed by the CU MWR and compared it with the in situ tower observations including all dates between 9 March and 7 May (Fig. 12a). Statistics indicate that for the lapse rate of temperature measured by the CU MWR and the in situ tower measurements, the MAE was about $2.1 \mathrm{~K} \mathrm{~km}^{-1}$ with an $R^{2}$ of 0.91 .

The same analysis was performed for the lapse rate of virtual temperature $\left(\gamma_{T_{\mathrm{v}}}=-\mathrm{d} T_{\mathrm{v}} / \mathrm{d} z\right)$ computed between the first and fourth level of the $915 \mathrm{MHz}$ RASS measurements (120-307 m) with the in situ tower observations (Fig. 12b) and the first and second level of the $449 \mathrm{MHz}$ RASS measurements (217-322 m) with the in situ tower observations (Fig. 12c). To have a compatible comparison between the ability of the MWR at measuring lapse rate and that of the RASSs, we computed the same statistics (MAE, bias, $R^{2}$, slope) presented in Fig. 12a, but first interpolating the $\mathrm{CU}$ MWR observations over the heights covered by the $915 \mathrm{MHz}$ RASS (120-307 m) and later interpolating the CU MWR observations over the heights covered by the $449 \mathrm{MHz}$ RASS (217-322 m). The first gave an $R^{2}=0.89$ for the CU MWR and $R^{2}=0.81$ for the $915 \mathrm{MHz}$ RASS, while the second gave an $R^{2}=0.79$ for the CU MWR and $R^{2}=0.6$ for the $449 \mathrm{MHz}$ RASS, resulting in the best $R^{2}$ for the MWR.
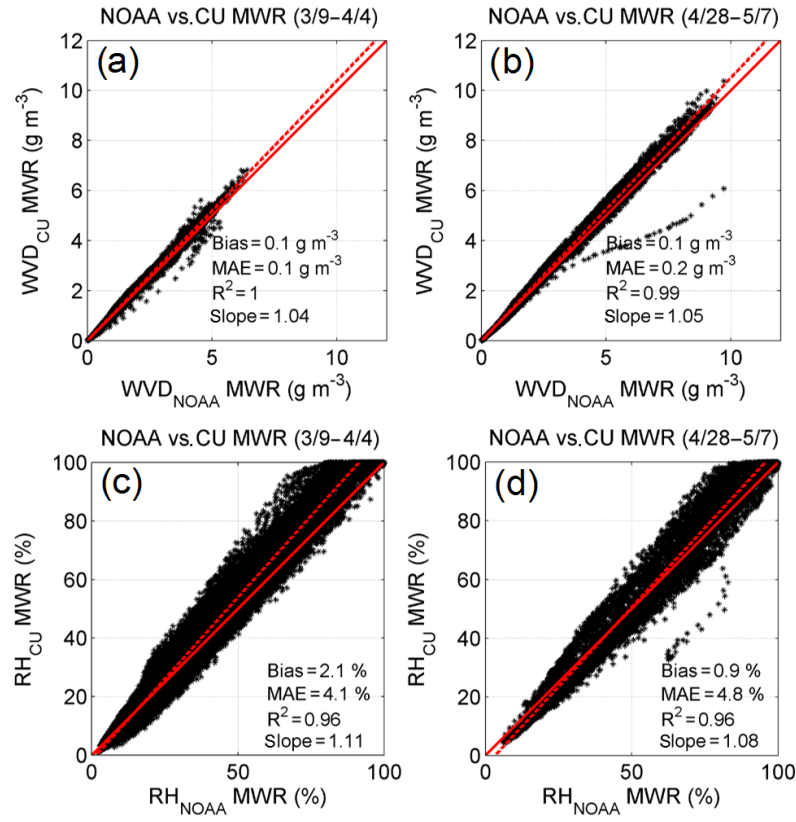

Figure 15. Comparison between (a)-(b) WVD and (c)-(d) RH observed by CU MWR and NOAA MWR between 9 March-4 April 2015 (a, c) and 28 April-7 May 2015 (b, d). The missing days in April coincide with the failure of the NOAA MWR surface sensor. One-on-one line is indicated as a solid red line and the regression as a dashed red line.

In addition to the $\gamma_{T}$ and $\gamma_{T_{\mathrm{v}}}$, we calculated the lapse rate of potential temperature from CU MWR measurements, as $\gamma_{\theta}=-\mathrm{d} \theta / \mathrm{d} z$ (differences with the lapse rate of virtual potential temperatures were practically unnoticeable). The statistics (MAE, bias, $R^{2}$, slope) were calculated for $\gamma_{\theta}$ using different tower levels, and the results are presented in Table 2. We note that the agreement between the lapse rate of potential temperature measured by the CU MWR and the in situ tower measurements is best when it is computed between 50 and $300 \mathrm{~m}$ (larger $\mathrm{d} z$ ), with a coefficient of determination of 0.91 . A comparison between the time series of $\gamma_{\theta}$ (between 50 and $300 \mathrm{~m}$ ) as computed by the in situ tower measurements and the CU MWR, respectively, is presented in Fig. 13 for all dates between 9 March and 7 May. The CU MWR follows the diurnal cycle of $\mathrm{d} \theta / \mathrm{d} z$ quite well, with the largest differences occurring at the minimum and maximum values. 

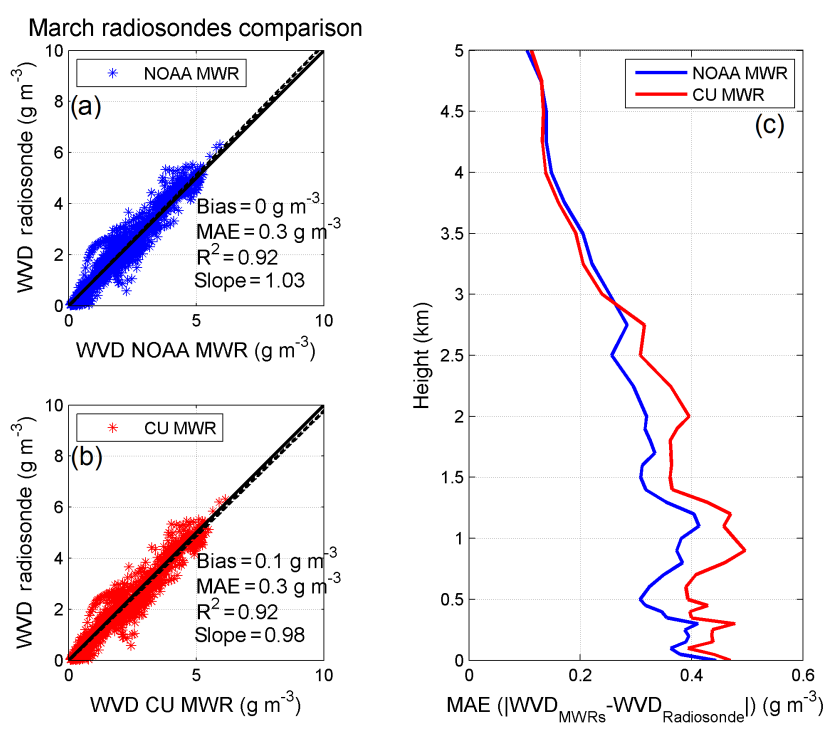

Figure 16. MWR vs. radiosonde comparison of WVD over the March period of 38 radiosonde launches. (a)-(b) are one-toone comparisons of WVD observed by the radiosondes and the (a) NOAA and (b) CU MWR between the surface and $5 \mathrm{~km}$ a.g.1. One-on-one line is indicated as a solid black line and the regression as a dashed black line. (c) Vertical profiles of MAE for the same variable.

To better quantify the differences in temperature between the CU MWR and the in situ observations, the data set was finally divided into times when the atmosphere was stable $(\mathrm{d} \theta / \mathrm{d} z \geq 0)$ and unstable $(\mathrm{d} \theta / \mathrm{d} z<0)$, based on the observations conducted by the CU MWR presented in Fig. 13. Temperatures observed by the CU MWR were compared during stable and unstable conditions to in situ tower observations at six height levels between 50 and $300 \mathrm{~m}$. Note that stable conditions might generate profiles with an inversion at the surface. Smaller MAEs occurred in unstable conditions (MAE $=0.8 \mathrm{~K}$; Fig. 14a) compared to stable conditions $(\mathrm{MAE}=1.2 \mathrm{~K} ;$ Fig. 14b). Larger MAE values in stable conditions might indicate that the MWR has difficulties accurately capturing the depth and the slope of the surface inversion. Similarly, the bias was smaller, and $R^{2}$ was larger, in unstable conditions compared to stable conditions.

\section{Accuracy of the MWR water vapor density and humidity profiles}

Differences in water vapor density and relative humidity between the two MWRs were analyzed before comparing to sounding observations. Profiles derived from averaged offzenith $15^{\circ}$ elevation MWR scans between the surface and $10 \mathrm{~km}$ a.g.l. were compared during the time periods when both instruments were functioning (9 March-4 April 2015 in Fig. 15a-c; 28 April-7 May 2015 in Fig. 15b-d). For the WVD comparison, the MAEs for the two MWR sys-
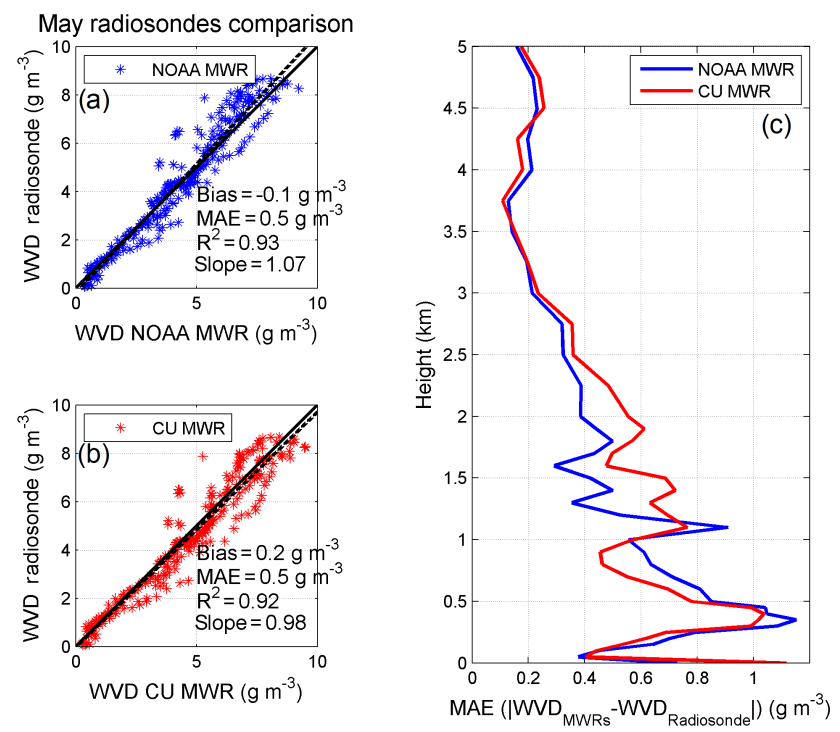

Figure 17. Same as in Fig. 16, but for the May period of 13 radiosonde launches.
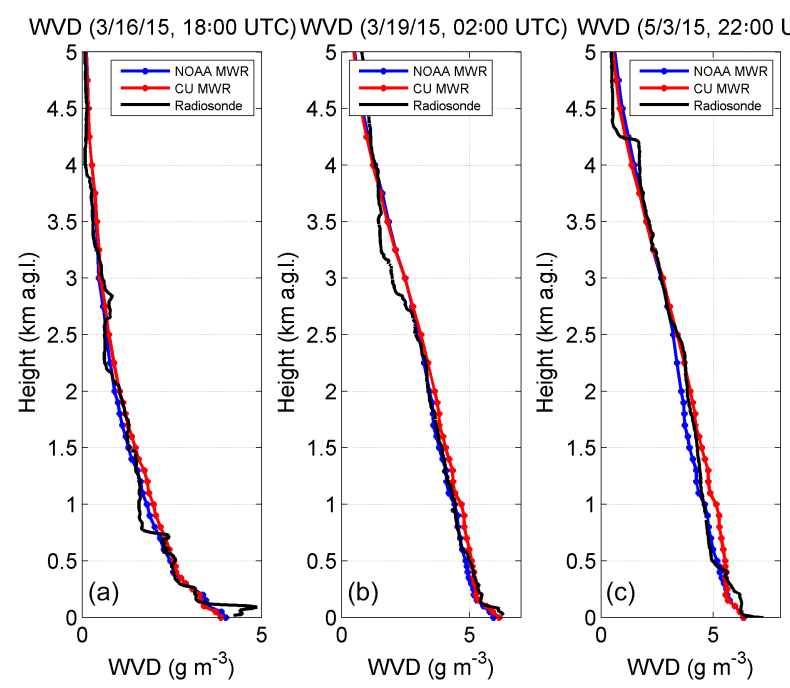

Figure 18. Vertical profiles of WVD as observed by MWRs (blue line: NOAA MWR; red line: CU MWR) and radiosonde (black line) at (a) 18:00 LT (00:00 UTC) on 16 March, (b) 02:00 LT (08:00 UTC) on 19 March, and (c) 22:00 LT (04:00 UTC) on 3 May 2015.

tems were 0.1 and $0.2 \mathrm{~g} \mathrm{~m}^{-3}$, the biases were $\sim 0.1 \mathrm{~g} \mathrm{~m}^{-3}$, and both $R^{2}$ s were close to 1 (Fig. 15a-b). For the RH comparison, the MAEs were 4.1 and $4.8 \%$, the biases were 2.1 and $0.9 \%$, and the coefficients of determination were both 0.96 (Fig. $15 \mathrm{c}-\mathrm{d}$ ). The values of bias, $R^{2}$, and slope indicated a good agreement between the instruments over the periods during which they were both functioning properly.

Lastly, water vapor density and relative humidity derived from the MWRs between the surface and $5 \mathrm{~km}$ a.g.l. are compared to radiosonde observations from March, April, 

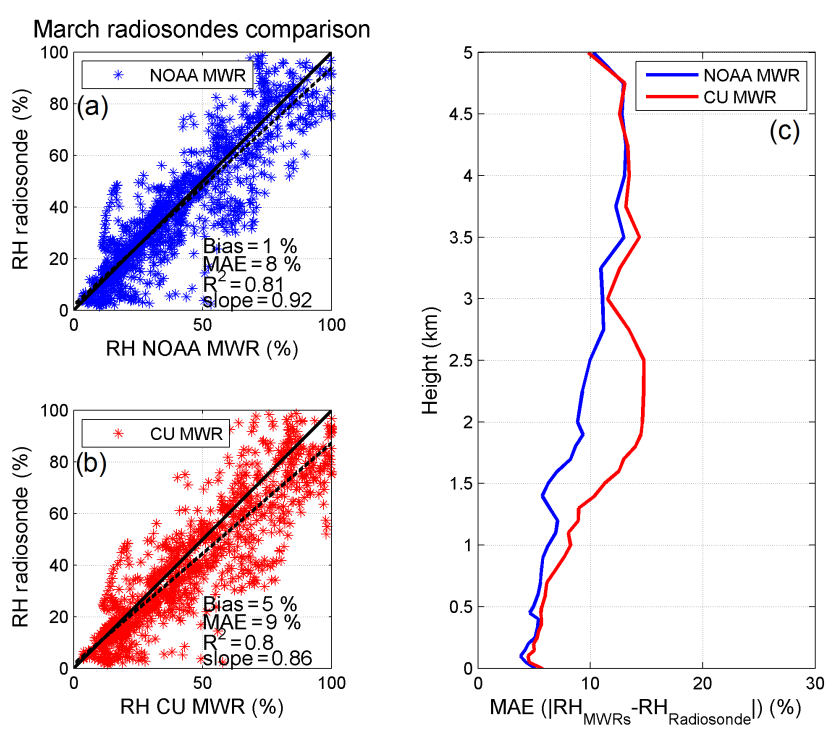

Figure 19. MWR vs. radiosonde comparison of RH over the March period of 38 radiosonde launches. (a)-(b) are one-to-one comparisons of RH observed by the radiosondes and the (a) NOAA and (b) CU MWR between the surface and $5 \mathrm{~km}$ a.g.l. One-on-one line is indicated as a solid black line and the regression as a dashed black line. (c) Vertical profiles of MAE for the same variable.

and May (Figs. 16-18 for WVD; Figs. 19-21 for RH). For WVD, in March (Fig. 16) and April (not shown), MAEs for both instruments show values equal to $0.3 \mathrm{~g} \mathrm{~m}^{-3}$, also reported by Cimini et al. (2011); the biases were close to $0 \mathrm{~g} \mathrm{~m}^{-3}$, and the coefficients of determination were 0.92 (Fig. 16a-b). Vertical profiles of MAE (Fig. 16c) show values of about $0.3-0.2 \mathrm{~g} \mathrm{~m}^{-3}$ up to $3-3.5 \mathrm{~km}$, with decreasing MAE above $3.5 \mathrm{~km}$. Larger MAEs were observed for WVD in May (Fig. 17) compared to March and April. MAE is equal to $0.5 \mathrm{~g} \mathrm{~m}^{-3}$ (Fig. 17a-b), with $R^{2}$ values of about 0.92 . Vertical profiles of MAE in May indicate larger values below $2.5 \mathrm{~km}$, where WVD profiles from the sounding showed more variability, decreasing above. Overall MWRs are able to follow the radiosonde vertical profile of WVD as presented in Fig. 18, although some information is missed due to the coarser MWRs resolution compared to the resolution of the sounding observations.

For RH, MAEs for both instruments show values below $10 \%$ in March (Fig. 19a-b). A relatively large scatter $\left(R^{2}\right.$ of $\sim 0.8$ ) is an indication of large variation in relative humidity. Some of the variability and associated large scatter might be attributed to the sounding encountering different air masses or even clouds at higher altitudes, as indicated by the vertical profiles of MAE. These profiles show that the MAEs are about 5-8\% below $\sim 1 \mathrm{~km}$, with the MAEs continuously increasing with increasing height (Fig. 20c). Larger MAEs were observed in April (not shown) and May (Fig. 20) compared to March (Fig. 19). MAEs range between $11 \%$ (in May) and $14 \%$ (in April, not shown), with $R^{2}$ val-
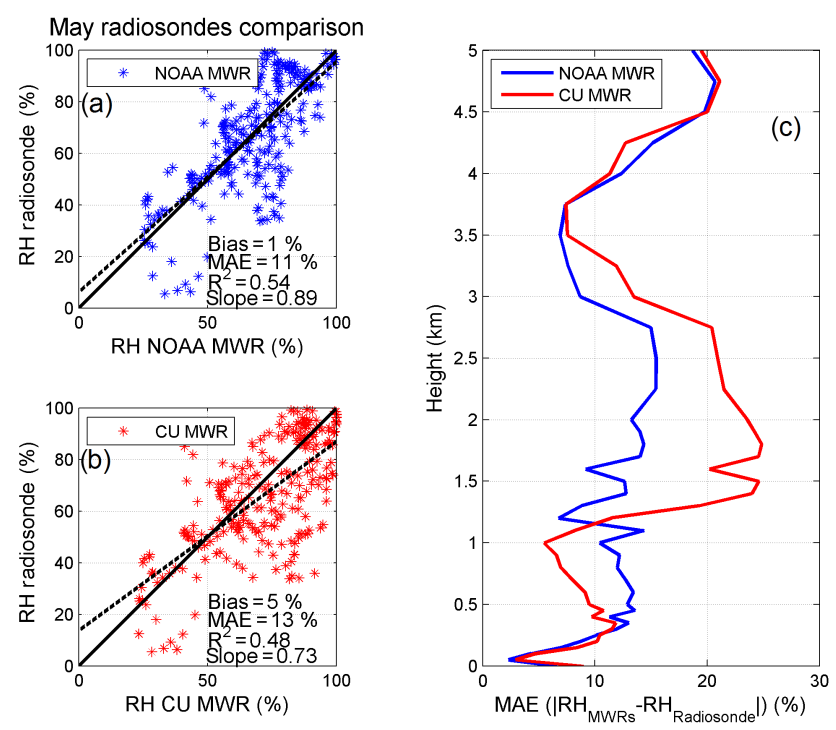

Figure 20. Same as in Fig. 19, but for the May period of 13 radiosonde launches.
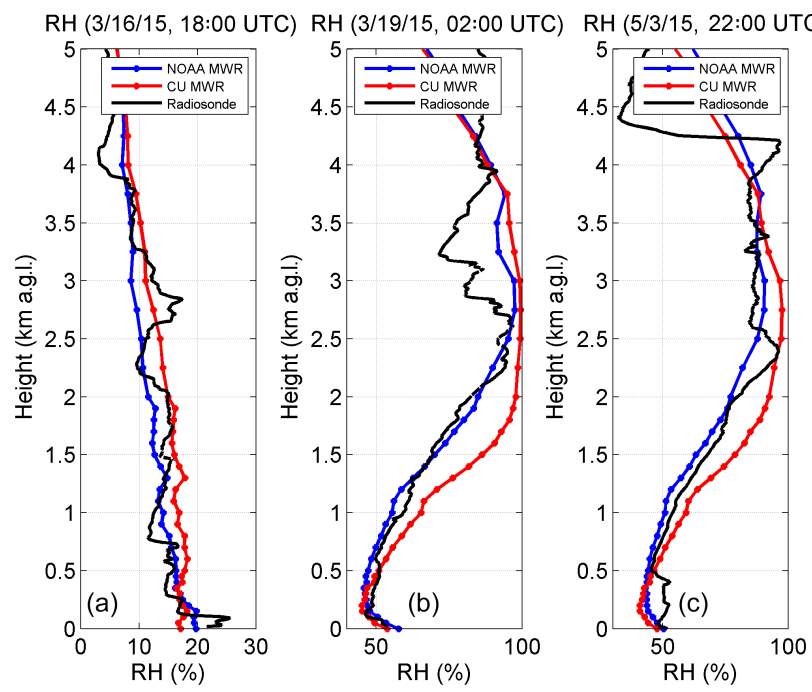

Figure 21. Vertical profiles of RH as observed by MWRs (blue line: NOAA MWR; red line: CU MWR) and radiosonde (black line) at (a) 18:00 LT (00:00 UTC) on 16 March, (b) 02:00 LT (08:00 UTC) on 19 March, and (c) 22:00 LT (04:00 UTC) on 3 May 2015.

ues of about 0.5. Vertical profiles of MAE in April and May indicate a similar pattern compared to March. Lower values (5-12\%) were observed below $\sim 1 \mathrm{~km}$, while larger values occurred around $1 \mathrm{~km}$ and between 3 and $4 \mathrm{~km}$. Since the three-dimensional humidity field is highly variable and strongly depends whether or not the instruments (both MWR and sounding) encountered clouds, the large MAEs between 1 and $4 \mathrm{~km}$ are most likely due to changes in air mass or the existence of clouds.

High-resolution soundings with vertical resolution of few meters show much more detail compared to the smooth 
MWR humidity profiles, as seen in Fig. 21. These examples show that while the MWRs are capable of reproducing the general trend compared to sounding observations, differences between the MWR and the sounding can be as high as $20-25 \%$.

\section{Conclusions}

Data collected during the XPIA campaign in spring 2015 were used to assess the accuracy of temperature, water vapor density, and relative humidity profiles from two MWRs, one $915 \mathrm{MHz}$ WPR-RASS system, and one $449 \mathrm{MHz}$ WPRRASS system with respect to in situ reference measurements from 61 radiosonde launches and temperature and relative humidity measurements at six different levels from a $300 \mathrm{~m}$ co-located atmospheric tower. Results indicate a mean absolute error in the temperature retrieved by the MWRs below $1.5 \mathrm{~K}$ for the layer of the atmosphere up to $5 \mathrm{~km}$. However, the details of the inversions were consistently in error, with the MWRs too cold at the surface and too warm above $250 \mathrm{~m}$. Our results revealed that the overall statistics for MWRs temperature measurements were slightly better for unstable conditions than stable conditions with temperature inversions at the surface, while the overall statistics for MWR temperature measurements were not particularly compromised during rainy conditions compared to rain-free conditions. In addition, we find consistent behavior of the MWRs among the different months and similar error statistics for different times of the day.

For the RASSs we found a mean absolute error in the virtual temperature below $0.8 \mathrm{~K}$ in the layer of the atmosphere covered by these measurements (up to approximately 1.6$2 \mathrm{~km}$ ) and that using the values of $T_{\mathrm{v}}$ corrected for the vertical velocity can decrease temperature accuracy and should only be used with caution. For this data set, the correction for the vertical velocity applied to calculate $T_{\mathrm{V}}$ was not beneficial to the accuracy of RASS measurements of $T_{\mathrm{v}}$ under any weather condition. In general the RASSs have overall lower error statistics than the MWRs for the layer of the atmosphere covered by the RASSs.

We additionally assessed the accuracy of these remotesensing instruments at measuring atmospheric stability conditions in the lower boundary layer, finding a coefficient of determination between the lapse rate measured by the MWR and the tower measurements over the tower levels between 50 and $300 \mathrm{~m}$ ranged from 0.76 to 0.91 , with the best value (0.91) found when the lapse rate was computed between $50 \mathrm{~m}$ and $300 \mathrm{~m}$ (larger $\mathrm{d} z$ ). These positive results demonstrate that profiling microwave radiometers can be useful for understanding conditions that can lead to strong vertical wind shear or turbulence, which can affect the loads on rotors.

We also assessed the accuracy of MWRs at retrieving water vapor density profiles, finding a mean absolute error below $0.5 \mathrm{~g} \mathrm{~m}^{-3}$ for the layer of the atmosphere up to $5 \mathrm{~km}$.
Finally, our study unsurprisingly revealed that relative humidity profiles measured by the MWR lack high resolution details compared to radiosonde measurements, with differences between the MWR and the sounding that can be as high as $20-25 \%$ and on average, for the layer of the atmosphere up to $5 \mathrm{~km}$, of the order of $8-14 \%$. For this reason, our future research will utilize the unique data set collected for XPIA to combine the information obtained from WPR potential refractivity profiles and from MWR potential temperature profiles to improve the accuracy of atmospheric humidity profiles (Bianco et al., 2005).

Data availability. The XPIA dataset is available to the public online (https://a2e.energy.gov/projects/xpia; Lundquist et al., 2016).

Competing interests. The authors declare that they have no conflict of interest.

Acknowledgements. The authors wish to acknowledge the two anonymous Referees for the useful suggestions that improved the paper and Alex St. Pé from the University of Maryland, Baltimore County, as well as the University of Colorado Boulder students Joseph C.-Y. Lee, Paul Quelet, Clara St. Martin, Brian Vanderwende, and Rochelle Worsnop who launched the radiosondes and Timothy Lim of NCAR for providing them careful training. We are very grateful for the assistance received from Radiometrics Corporation in setting up and comparing the two MWRs calibrations. Thanks go to the University of Colorado Boulder students Joshua Aikins and Evan Kalina who set up the CU radiometer. We express appreciation to the National Science Foundation for supporting the CABL deployments (https://www.eol.ucar.edu/field_projects/cabl) of the MGAUS radiosondes and the tower instrumentation. We thank the Lefthand Water District for providing access to the Water Tank site. We would like to acknowledge operational, technical, and scientific support provided by NCAR's Earth Observing Laboratory, sponsored by the National Science Foundation, as well as by Timothy Coleman and the group of engineers of NOAA/PSD. Partial support for the UMBC deployments was provided by the Maryland Energy Administration. NREL is a national laboratory of the US Department of Energy, Office of Energy Efficiency and Renewable Energy, operated by the Alliance for Sustainable Energy, LLC. Funding for this work was provided by the US Department of Energy, Office of Energy Efficiency and Renewable Energy, Wind and Water Power Technologies Office, and by NOAA's Earth System Research Laboratory.

Edited by: W. Shaw

Reviewed by: two anonymous referees 


\section{References}

Angevine, W. M. and W. Ecklund: Errors in radio acoustic sounding of temperature, J. Atmos. Ocean. Technol., 11, 837-842, 1994.

Angevine, W. M., Bakwin, P. S., and Davis, K. J.: Wind profiler and RASS measurements compared with measurements from a 450 m-tall tower, J. Atmos. Ocean. Technol., 15, 818-825, 1998.

Bianco, L., Cimini, D., Marzano, F. S., and Ware, R.: Combining microwave radiometer and wind profiler radar measurements for high-resolution atmospheric humidity profiling, J. Atmos. Ocean. Technol., 22, 949-965, 2005.

Cimini, D., Campos, E., Ware, R., Albers, S., Giuliani, G., Oreamuno, J., Joe, P., Koch, S. E., Cober, S., and Westwater, E.: Thermodynamic atmospheric profiling during the 2010 Winter Olympics using ground-based microwave radiometry, IEEE T. Geosci. Remote, 99, 1-11, doi:10.1109/TGRS.2011.2154337, 2011.

Crewell, S. and Löhnert, U.: Accuracy of boundary layer temperature profiles retrieved with multifrequency multiangle microwave radiometry, IEEE T. Geosci. Remote, 45, 2195-2201, doi:10.1109/TGRS.2006.888434, 2007.

Ecklund, W. L., Carter, D. A., and Balsley, B. B. A.: UHF wind profiler for the boundary layer: brief description and initial results, J. Atmos. Ocean. Technol., 5, 432-41, 1988.

Ecklund, W. L., Carter, D. A., Balsley, B. B., Currier, P. E., Green, J. L., Weber, B. L., Gage, K. S.: Field tests of a lower tropospheric wind profiler, Radio Sci., 25, 899-906, doi:10.1029/RS025i005p00899, 1990.

Friedrich, K., Lundquist, J. K., Aitken, M., Kalina, E. A., and Marshall, R. F.: Stability and turbulence in the atmospheric boundary layer: A comparison of remote sensing and tower observations, Geophys. Res. Lett., 39, L03801, doi:10.1029/2011GL050413, 2012.

Görsdorf, U. and Lehmann, V.: Enhanced Accuracy of RASSMeasured Temperatures Due to an Improved Range Correction, J. Atmos. Ocean. Technol., 17, 406-416, 2000.

Güldner, J. and Spänkuch, D.: Remote sensing of the thermodynamic state of the atmospheric boundary layer by ground-based microwave radiometry, J. Atmos. Ocean. Technol., 18, 925-933, 2001.

Hansen, K. S., Barthelmie, R. J., Jensen, L. E., and Sommer, A.: The impact of turbulence intensity and atmospheric stability on power deficits due to wind turbine wakes at Horns Rev wind farm, Wind Energy, 15, 183-196, doi:10.1002/we.512, 2012.

Han, Y. and Westwater, E. R.: Analysis and improvement of tipping calibration for ground-based microwave radiometers, IEEE T. Geosci. Remote, 38, 1260-1276, doi:10.1109/36.843018, 2000.

Horst, T. W., Semmer, S. R., and Bogoev, I.: Evaluation of Mechanically-Aspirated Temperature/Relative Humidity Radiation Shields, 18th Symposium on Meteorological Observation and Instrumentation, AMS Annual Meeting, New Orleans, LA, 10-15 January 2015, available at: https://ams.confex.com/ams/ 96Annual/webprogram/Paper286839.html (last access: 4 May 2017), 2016.

Liljegren, J., Lesht, B. M., Kato, S., and Clothiaux, E.: Initial evaluation of profiles of temperature, water vapor and cloud liquid water from a new microwave profiling radiometer, in: Preprints, 11th Symp. on Meteorological Observations and Instrumentation, Albuquerque, NM, January 2001, Amer. Meteor.
Soc., 8, available at: http://radiometrics.com/data/uploads/2012/ 11/MWRP_ARM01.pdf (last access: 4 May 2017), 2001.

Löhnert, U. and Maier, O.: Operational profiling of temperature using ground-based microwave radiometry at Payerne: prospects and challenges, Atmos. Meas. Tech., 5, 1121-1134, doi:10.5194/amt-5-1121-2012, 2012.

Lundquist, J. K., Wilczak, J. M., Ashton, R., Bianco, L., Brewer, W. A., Choukulkar, A., Clifton, A., Debnath, M., Delgado, R., Friedrich, K., Gunter, S., Hamidi, A., Iungo, G. V., Kaushik, A., Kosović, B., Langan, P., Lass, A., Lavin, E., Lee, J. C.-Y., McCaffrey, K. L., Newsom, R. K., Noone, D. C., Oncley, S. P., Quelet, P. T., Sandberg, S. P., Schroeder, J. L., Shaw, W. J., Sparling, L., St. Martin, C., St. Pe, A., Strobach, E., Tay, K., Vanderwende, B. J., Weickmann, A., Wolfe, D., and Worsnop, R.: Assessing state-of-the-art capabilities for probing the atmospheric boundary layer: the XPIA field campaign, B. Am. Meteorol. Soc., 98, 289-314, doi:10.1175/BAMS-D-15-00151.1, 2016.

Marquis, M., Wilczak, J., Ahlstrom, M., Sharp, J., Stern, A., Smith, J. C., and Calvert, S.: Forecasting the wind to reach significant penetration levels of wind energy, B. Am. Meteorol. Soc., 92, 1159-1171, doi:10.1175/2011BAMS3033.1, 2011.

May P. T., Moran, K. P., and Strauch, R. G.: The Accuracy of RASS Temperature Measurements, J. Appl. Meteorol., 28, 1329-1335, 1989.

Moran, K. P. and Strauch, R. G.: The Accuracy of RASS Temperature Measurements Corrected for Vertical Air Motion, J. Atmos. Ocean. Technol., 11, 406-4016, 1994.

North, E. M., Peterson, A. M., and Parry, H. D.: RASS, a remote sensing system for measuring low-level temperature profiles, B. Am. Meteorol. Soc., 54, 912-919, 1973.

Reehorst, A. L.: Comparison of profiling microwave radiometer, aircraft, and radiosonde measurements from the Alliance Icing Research Study (AIRS), NASA/TM-2001-211101, 12 pp., available at: http://ntrs.nasa.gov/archive/nasa/casi.ntrs.nasa.gov/ 20010098322.pdf, 2001.

Rosenkranz, P. W.: Water vapor microwave continuum absorption: A comparison of measurements and models, Radio Sci., 33, 919 928, 1998.

Solheim, F., Godwin, J., and Ware, R.: Passive ground-based remote sensing of atmospheric temperature, water vapor, and cloud liquid water profiles by a frequency synthesized microwave radiometer, Meteorol. Z., 7, 370-376, 1998a.

Solheim, F., Godwin, J., Westwater, E., Han, Y., Keihm, S., Marsh, K., and Ware, R.: Radiometric profiling of temperature, water vapor and cloud liquid water using various inversion methods, Radio Sci., 33, 393-404, 1998b.

Strauch, R. G., Merritt, D. A., Moran, K. P., Earnshaw, K. B., and Van De Kamp, D.: The Colorado wind-profiling network, J. Atmos. Ocean. Technol., 1, 37-49, 1984.

Vanderwende, B. J. and Lundquist, J. K.: The modification of wind turbine performance by statistically distinct atmospheric regimes, Environ. Res. Lett., 7, 034035, doi:10.1088/17489326/7/3/034035, 2012.

Ware, R., Carpenter, R., Güldner, J., Liljegren, J., Nehrkorn, T., Solheim, F., and Vandenberghe, F.: A multichannel radiometric profiler of temperature, humidity, and cloud liquid, Radio Sci., 38, doi:10.1029/2002RS002856, 2003. 
Wharton, S. and Lundquist, J. K.: Atmospheric stability affects wind turbine power collection, Environ. Res. Lett., 7, 014005, doi:10.1088/1748-9326/7/1/014005, 2012.
Xu, G., Ware, R., Zhang, W., Feng, G., Liao, K., Liu, Y.: Effect of off-zenith observations on reducing the impact of precipitation on ground-based microwave radiometer measurement accuracy, Atmos. Res., 140-141, 85-94, 2014. 